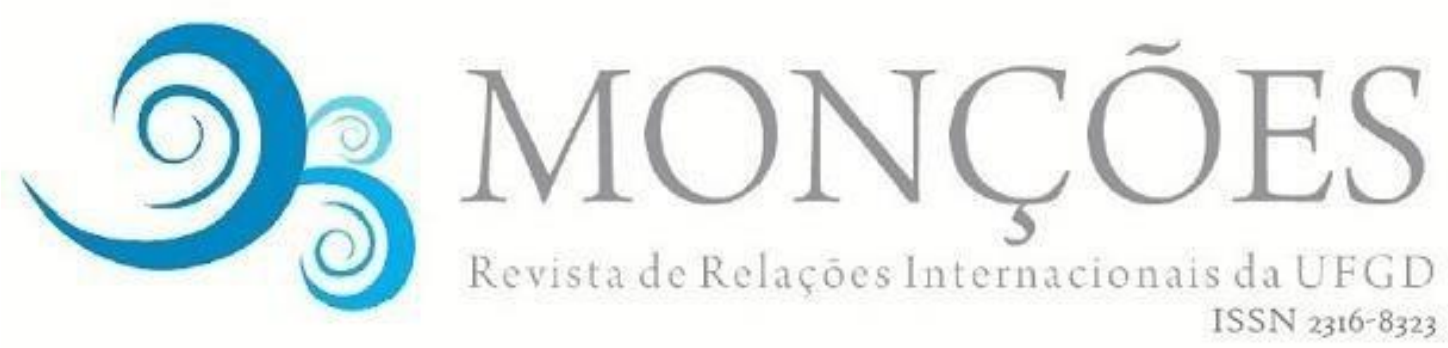

\title{
A DIMENSÃO SOCIAL DA INTEGRAÇÃO MERCOSULINA: UMA ANÁLISE SOBRE O PROJETO MERCOSUL SOCIAL
}

\author{
ELIAS DAVID MORALES MARTINEZ \\ Professor do Bacharelado em Relações Internacionais - Universidade Federal do ABC \\ - UFABC e Doutor em Integração Regional pelo PROLAMUSP. \\ JESSICA GOMES MACHADO \\ Mestre em Relações Internacionais - Universidade Estadual da Paraíba - UEPB. \\ Mestre em Direitos Humanos, Cidadania e Políticas Públicas - Universidade Federal \\ da Paraíba - UFPB.
}

RESUMO: O Mercado do Cone Sul (MERCOSUL) foi criado em 1991 como um acordo de base comercial, mas ultimamente tem evoluído para uma maior integração de cunho social. O presente artigo faz um balanço do Projeto Mercosul Social e avalia as conquistas que nessa área tem sido alcançadas. Assim, se evidencia a existência do aparato institucional do Mercosul Social apresentando quatro iniciativas devidamente analisadas: o "Programa Somos Mercosul", as "Cúpulas Sociais", o "Instituto do Mercosul" e o "Programa Mercosul Social e Participativo". O estudo pretende afirmar que o projeto do Mercosul Social representa um amadurecimento da integração regional, indo além das questões meramente comerciais e, portanto, ele deve ser aprimorado, pois a participação social tem se tornado um instrumento de aproximação entre o bloco e a sociedade civil.

Palavras-chave: Dimensão social, Projeto Mercosul Social, Sociedade Civil, Mercosul, Integração regional.

\section{THE SOCIAL DIMENSION OF THE MERCOSUR INTEGRATION: AN ANALYSIS ABOUT THE MERCOSUR SOCIAL PROJECT}

\begin{abstract}
The Common Market of the South (MERCOSUR) was created in 1991 as a commercial basis agreement, but recently evolved to a agreement focused in social coverage integration. This article affords an analysis of the Mercosur Social Project and evaluates the achievements in this area. Therefore, the existence of the institutional apparatus of the Mercosur Social is evinced by presenting four initiatives properly analyzed: "Somos Mercosul", "Cúpulas Sociais", "Instituto social do Mercosul" and "Programa Mercosul Social e Participativo". This research claims to assert that the Mercosur Social Project represents a maturation of regional integration, overcoming the purely commercial issues, so yet that should be improved, because social participation has become a way of access between the bloc and the civil society.
\end{abstract}

Keywords: Social dimension, Social Mercosur Project, Civil Society, Mercosur, Regional Integration. 


\title{
LA DIMENSIÓN SOCIAL DE LA INTEGRACIÓN MERCOSURINA: UN ANÁLISIS DEL PROYECTO MERCOSUR SOCIAL
}

\begin{abstract}
RESUMEN: El Mercado del Cono Sur (MERCOSUR) fue creado en 1991 como un acuerdo de base comercial, sin embargo, últimamente ha evolucionado hacia una mayor integración de cuño social. El presente artículo hace un balance del Proyecto Mercosur Social y evalúa las conquistas que en esa área han sido alcanzadas. Así, se evidencia la existencia del aparato institucional del Mercosur Social presentando cuatro iniciativas debidamente analizadas: el "Programa Somos Mercosur", las "Cumbres Sociales", el "Instituto del Mercosur" y el "Programa Mercosur Social y Participativo". El estudio pretende afirmar que el Proyecto Mercosur Social representa una madurez de la integración regional, más allá de las cuestiones meramente comerciales y, por lo tanto, debe ser mejorado, pues la participación social se ha convertido en un instrumento de acercamiento entre el bloque y la sociedad civil.
\end{abstract}

Palabras clave: Dimensión Social; Proyecto Mercosur Social; Sociedad Civil, Mercosur, Integración Regional

\section{LA DIMENSION SOCIALE DU MERCOSUR : UNE ANALYSE SUR LE PROJET MERCOSUR SOCIAL}

RESUME: Le Marché Commun du Cône Sud (MERCOSUR) a été créé en 1991 sur la base d'un accord à but commercial, mais il a récemment évolué vers une plus grande intégration du domaine social. Le présent article fait un bilan du Projet Mercosur Social et évalue les conquêtes obtenues dans ce domaine. Ainsi, il met en exergue l'existence d'un cadre institutionnel du Mercosur Social en présentant quatre initiatives dûment analysées: Le "Programme Nous Sommes Mercosur", les "Sommets Sociaux", "L'Institut du Mercosur" et le "Programme Mercosur Social et Participatif'. Cette étude prétend affirmer que le projet Mercosur Social représente une maturation de l'intégration régionale, qui va bien au-delà des sujets purement commerciaux et, de ce fait, il doit être amélioré, car la participation sociale devient un moyen de favoriser le rapprochement entre le Mercosur et la société civile.

Mots-Clés : Dimension Sociale, Mercosur Social et Participatif, Société Civile, Mercosur, l'intégration régionale

\section{INTRODUÇÃO}

A integração sul-americana registrou importantes avanços nos últimos anos, e o Mercado Comum do Sul (Mercosul) têm contribuído de forma decisiva para que tais progressos ocorram. Nesse sentido, é fundamental demonstrar as conquistas que advém em áreas não tradicionais e que vão além das questões comerciais e econômicas. Como prova disso, nos últimos anos, o Mercosul vem implementando uma intensa agenda na área social com o intuito de superar o déficit de participação popular existente no bloco. 
O Mercosul tem se destacado atualmente pelo fato de se desempenhar como elemento importante na disseminação de programas e iniciativas baseadas no caráter social e participativo. Através destes empreendimentos, a sociedade civil ganha cada vez mais espaço na medida em que se torna ator relevante nos novos mecanismos de participação que surgem para equilibrar a baixa representatividade social.

As iniciativas sociais do Mercosul são fundamentais, pois, de uma lado constroem uma nova agenda regional, focada na integração das políticas sociais, e de outro, adotam um método distinto de condução de políticas mais transparentes e de forma participativa. Assim sendo, este bloco, pretende cada vez mais estreitar a relação da sociedade civil na formulação dos seus interesses, abrindo espaço para políticas de cunho social e de forte impacto. Por tanto, o Mercosul vai além dos acordos de comércio e pretende estabelecer um compromisso democrático baseado em iniciativas que abrem caminho para que a sociedade civil tenha voz direta na decisões regionais que tangem aos países que integram o grupo.

O Projeto do Mercosul Social e Participativo é a articulação política entre os governos, organizações e movimentos sociais interessados na abertura do bloco à democracia participativa. Nesse sentido, pretende-se através deste artigo, fazer um balanço desse empreendimento, através de uma sistematização das informações relevantes sobre as diversas iniciativas, e, assim, avaliar a situação das conquistas sociais do bloco. Interessante destacar que, a partir do ano 2001, começa uma percepção ao interior do bloco, apoiada pela vontade política dos governos progressistas, em lançar estratégias para interligar a parte comercial com a integração social do grupo.

Assim sendo, pretende-se discutir as iniciativas implementadas pelo bloco, como o "Somos Mercosul", "Instituto Social do Mercosul", "Cúpulas Sociais" e o "Programa Mercosul Social e Participativo". Igualmente, busca-se esclarecer alguns pontos relevantes acerca do funcionamento destes órgãos de participação social, tendo em conta, além do funcionamento e efetividade, os objetivos com os quais foram desenhados atentando aos contextos em que tais programas emergiram. 


\section{UMA ANÁLISE SOBRE O ASPECTO SOCIAL NO MERCOSUL}

O Mercosul foi criado logo no inicio da década de 1990 como um acordo de complementação comercial entre os países membros. No entanto, recentemente o bloco tem evoluído com mais força para uma integração econômica, política e social de forma equilibrada. Isto significa que os países da região tem decidido enfrentar os desafios que a globalização atual representa, através de uma maior aproximação entre os diferentes membros do processo integrador, mas com uma estratégia de implementação social (MERCOSUL SOCIAL E PARTICIPATIVO: CONSTRUINDO O MERCOSUL DOS POVOS COM DEMOCRACIA E CIDADANIA, 2007).

O Projeto do Mercosul Social ${ }^{1}$ tem suas origens em 2001 a partir da Reunião de Ministros e Autoridades do Desenvolvimento Social do Mercosul e Estados Associados (RAMDS). Considerada como espaço institucional para o intercâmbio de experiências e de coordenação política de desenvolvimento social entre os países membros e associados, esta reunião teve como objetivo fortalecer a incidência social na busca do combate à pobreza na América do Sul, como também, estabelecer uma estratégia para coordenar políticas sociais voltadas para a região na área de saúde, educação, meio ambiente, direitos humanos, e igualdade de gênero entre outros (Idem, p. 24).

Estas questões de cunho social foram inseridas no Mercosul desde a formação do Foro Consultivo Econômico Social, âmbito no qual ocorreu durante a década de 1990, se tornou o espaço de representação da sociedade civil no bloco. Mas é a partir de 2003, quando foram desenvolvidos programas de incidência nacional, tais como o "Somos Mercosul" que veio fortalecer a participação de organizações sociais nos diferentes encontros do processo integrador mercosulino.

Tendo em vista a necessidade da incorporação de temas para além do comercial, em 2006, em Brasília, os chefes dos Estados-Membros do bloco realizaram a primeira Cúpula Social, essas cúpulas são espaços de discussão e formulação de propostas de políticas públicas, onde há participação de

\footnotetext{
1 Trata-se do aspecto eminentemente social do processo integrador mercosulino.
} 
movimentos sociais (MARTINS, et al. 2011). Assim, o bloco multiplicou as discussões e reuniões voltadas para as temáticas sociais, aumentando suas políticas de alcance regional nas áreas de educação, saúde, cultura e outros assuntos relacionados com a sociedade civil.

$\mathrm{Na}$ medida em que eram incorporados os debates de cunho social, o bloco percebeu a necessidade de se preocupar com a criação de espaços institucionais para a participação popular. O Foro Consultivo Econômico e Social, por exemplo, faz parte da primeira geração de participação social do bloco, a segunda geração corresponde ao programa Somos Mercosul e as Cúpulas Sociais do Mercosul, que abriram passo para políticas públicas em áreas socialmente sensíveis, assim, o "déficit de participação social que caracterizou o Mercosul durante a primeira década da integração começou a ser superado" (MARTINS, et. al. 2011, p. 138).

Foi assim que a agenda do Mercosul se voltou cada vez mais em direção a temas de desenvolvimento social, consolidando a emergência do programa ou projeto de tornar o Mercosul cada vez mais social e participativo (o que seria conhecido como o "Mercosul Social Participativo"). O lançamento da plataforma Somos Mercosul, a implementação das Cúpulas Sociais, o empreendimento do Instituto Social do Mercosul e o Programa Mercosul Social e Participativo foram as instancias institucionais que estruturaram o enfoque social que o processo de integração mercosulina tinha estabelecido para diversificar suas áreas de atuação para além da comercial.

Desde a criação desses mecanismos, o déficit da participação social começou ser superado, através da participação de movimentos sociais, de organizações de mulheres, de imigrantes, de programas de juventude, de trabalhadores, de pequenos empresários, de políticas de economia solidária. Essa aproximação entre Estado e sociedade civil produziu efeitos positivos para que os temas sociais ganhassem importância iniciando assim, um novo capítulo da integração regional como o surgimento do Mercosul Social e Participativo. (MARTINS, et. al. 2011).

Dessa forma, percebe-se que o Mercosul deixa de ser um bloco meramente comercial e passa a colocar um progressivo protagonismo para a sociedade civil, se tornando a grande beneficiada do processo. Assim, a integração do Cone Sul 
também demonstra uma gradual preocupação em afirmar um compromisso mais sólido na promoção dos Direitos Humanos. A proteção dos direitos fundamentais se vê fortalecida no surgimento de estratégias de cooperação contra a violência, discriminação sexual, racional e ética e na defesa dos direitos da criança e do adolescente.

Outras temáticas, também abordadas pelo Mercosul, são referentes à agricultura familiar, ao cooperativismo e à economia solidária. A saúde e o meio ambiente, igualmente são considerados temas de extrema importância. Outrossim, são contemplados, em relativa importância, a diversidade cultural, a comunicação social e as políticas locais de desenvolvimento, prezando pelo fortalecimento das políticas regionais que valorizem e respeitem a diversidade racial, ética e de gênero, contribuindo assim, com um maior intercâmbio de experiências e de comunicação entre os países (MERCOSUL SOCIAL E PARTICIPATIVO, 2008).

Interessante observar que no Tratado de Assunção que deu origem ao Mercosul, já existia um esboço para a criação de um espaço de diálogo com a sociedade civil. Apesar do Tratado não prever uma instância especificamente voltada para o desenvolvimento da dimensão social, podemos encontrar nele, uma breve referência ao aspecto social, logo no inicio do seu preâmbulo:

\footnotetext{
A República Argentina, a República Federativa do Brasil, a República do Paraguai e a República Oriental do Uruguai, doravante denominados "Estados Partes". Considerando que a ampliação das atuais dimensões de seus mercados nacionais, através da integração, constitui condição fundamental para acelerar os seus processos de desenvolvimento econômico com justiça social [...] (TRATADO DE ASSUNÇÃO, 1991, p. 1)
}

Posteriormente, com a assinatura do Protocolo Adicional de Ouro Preto, foi possível uma flexibilização participativa dentro do bloco, criando os primeiros espaços institucionais de participação extra-executiva, como a Comissão Parlamentar Conjunta e como o Foro Consultivo Econômico Social, que pode ser definido como o órgão de representação dos setores econômicos e sociais (VÁZQUEZ, 2007).

Com o intuito de diminuir o déficit social do Mercosul, o Foro Consultivo Econômico Social foi instituído no ano de 1995, tendo por objetivo inserir a 
sociedade civil no processo integrador. Entretanto, o Foro se constituía apenas por um órgão consultivo e não dispunha de recursos humanos, materiais e econômicos para realizar trabalhos e reuniões (FREITAS, 2009, p. 236-240). Ainda, no mesmo ano, ocorreu a formação e articulação da Rede Mercocidades, tornando-se uma ferramenta social que aproximou o governo local aos órgãos decisórios do bloco. A principal função desta rede foi a de buscar uma maior inserção dos governos locais nas políticas do Mercosul, tornando a integração mais democrática, facilitando assim, que as demandas locais fossem mais rapidamente conhecidas (RANZAN, 2011).

Conforme visto, no inicio da experiência mercosulina, a dimensão social não desempenhava lugar de destaque. Algum tempo depois, foi repensando um esquema integracionista agregando a questão social. Draibe (2006) explicita que a partir de 2000 , foram inseridos compromissos de justiça e igualdade na agenda do Mercosul, havendo um alargamento e utilização da complexidade dos objetivos da integração social.

Nessa mesma linha, em 2000, os presidentes dos Estados-partes do Mercosul, mais a Bolívia e o Chile, assinaram a Carta de Buenos Aires sobre o Compromisso Social no Mercosul, instruindo a:

[...] Fortalecer o trabalho conjunto entre os seis países, assim como o intercâmbio de experiências e informações, a fim de contribuir para a superação de problemas sociais mais agudos que os afetam e para definir os temas ou áreas onde seja viável uma ação coordenada ou complementar para solucioná-los (MERCOSUL SOCIAL E PARTICIPATIVO: CONSTRUINDO O MERCOSUL DOS POVOS COM DEMOCRACIA E CIDADANIA, 2007, p. 25).

Sendo assim, o documento deixa claro a necessidade de promoção e desenvolvimento de políticas em favor de uma melhor condição de vida para os cidadãos dos países do Mercosul. Essa Carta abriu o caminho para a institucionalização da Reunião de Ministros e Autoridades de Desenvolvimento Social do MERCOSUL (RMADS), constituindo desse modo, um espaço com a função de proporcionar medidas para orientar a coordenação de políticas de desenvolvimento e gerar ações conjuntas para o fortalecimento social dos Estados Parte. 
Iniciou-se, ao redor da RMADS, um ambiente de debates na busca de consensos e estratégias para lidar com o problema social do bloco. O conjunto de tais medidas adotadas foi chamado de Mercosul Social. A partir disso, e juntamente com outros órgãos do bloco, foram impulsionadas as ações fundamentais para atender o olhar social do Mercosul, tais como o "Programa Somos Mercosul", as "Cúpulas Sociais", o "Instituto Social do Mercosul" e o "Programa Mercosul Social e Participativo", como pode ser observado no quadro 1 a seguir:

Quadro 1 - Mecanismos Sociais do Mercosul

\begin{tabular}{|c|c|c|c|c|}
\hline INICIATIVA & PAIS SEDE & ANO & ENFOQUE & OBJETIVO \\
\hline $\begin{array}{l}\text { Programa } \\
\text { Somos } \\
\text { Mercosul }\end{array}$ & Uruguai & 2005 & $\begin{array}{l}\text { Superar o } \\
\text { déficit de } \\
\text { participação } \\
\text { popular } \\
\text { existente no } \\
\text { Mercosul }\end{array}$ & $\begin{array}{ll}\text { Desenvolver } & \text { a } \\
\text { cidadania } & \text { no } \\
\text { processo } & \text { de } \\
\text { integração } & \\
\text { regional, } \\
\text { gerando } \\
\text { espaços de } \\
\text { debate para a } \\
\text { sociedade civil e } \\
\text { os governos }\end{array}$ \\
\hline $\begin{array}{l}\text { Cúpula } \\
\text { Social do } \\
\text { Mercosul }\end{array}$ & $\begin{array}{l}\text { Realizada no } \\
\text { país que está } \\
\text { sob a } \\
\text { Presidência } \\
\text { Pro Tempore } \\
\text { do Mercosul }\end{array}$ & 2006 & $\begin{array}{l}\text { Estimular a } \\
\text { participação } \\
\text { da sociedade } \\
\text { civil }\end{array}$ & $\begin{array}{l}\text { Construir uma } \\
\text { agenda social e } \\
\text { adotar métodos } \\
\text { de decisões } \\
\text { transparentes, } \\
\text { participativas, } \\
\text { legítimas } \\
\text { democráticas }\end{array}$ \\
\hline $\begin{array}{l}\text { Instituto } \\
\text { Social do } \\
\text { Mercosul }\end{array}$ & Paraguai & 2007 & $\begin{array}{l}\text { Instância } \\
\text { técnica } \\
\text { permanente } \\
\text { de pesquisa } \\
\text { na área das } \\
\text { políticas } \\
\text { sociais }\end{array}$ & $\begin{array}{lr}\text { Promover } & \text { o } \\
\text { desenvolvimento } & \\
\text { humano integral, } \\
\text { através } & \text { de } \\
\text { estratégias } & \text { com } \\
0 \quad \text { intuito } & \text { de } \\
\text { reforçar } & \text { a } \\
\text { dimensão } & \text { social } \\
\text { do bloco. } & \\
\end{array}$ \\
\hline
\end{tabular}




\begin{tabular}{|l|l|l|l|l|}
\hline $\begin{array}{l}\text { Programa } \\
\text { Mercosul } \\
\text { Social e } \\
\text { Participativo }\end{array}$ & Brasil & 2008 & $\begin{array}{l}\text { Diálogo entre } \\
\text { o governo e a } \\
\text { sociedade } \\
\text { civil em torno } \\
\text { da integração } \\
\text { regional. }\end{array}$ & $\begin{array}{l}\text { Promover a } \\
\text { interlocução } \\
\text { entre } \\
\text { Governos e as } \\
\text { organizações da } \\
\text { sociedade civil } \\
\text { sobre políticas } \\
\text { públicas para o } \\
\text { Mercado do } \\
\text { Cone Sul do }\end{array}$
\end{tabular}

Fonte: Elaboração própria com base em: Alemani, C. e Leandro, B. (2006); Mercosul, et al. (2012).

\section{O PROGRAMA SOMOS MERCOSUL}

O Programa Somos Mercosul foi lançado em 2005 pela presidência prótempore do Uruguai, antecedendo a I Cúpula Social do bloco. Essa iniciativa corresponde a um processo de criação de uma esfera pública regional, resultado do amadurecimento da cultura democrática dentro do processo mercosulino, com o intuito de superar o déficit de participação social que, até então, caracterizava a integração regional (MARTINS, et. al. 2011).

Este programa nasceu com o objetivo de envolver a cidadania na integração regional, e favorecer a criação de espaços onde a sociedade civil e os governos possam debater a formulação de demandas e, participar dos processos decisórios do bloco. Os fundamentos que norteiam essa iniciativa são: 1) Democratização; 2) Esfera pública; 3) Transparência; 4) Controle social e 5) Supranacionalidade (idem, p. 139).

A iniciativa consiste em um conjunto de atividades e reuniões organizados, conjuntamente, pela presidência pro tempore e a sociedade civil. lgualmente, a iniciativa tem como preocupação a integração das cadeias produtivas, a superação das assimetrias regionais e a implementação de políticas sociais, contando sempre com a participação proativa da sociedade civil (MERCOSUL SOCIAL E PARTICIPATIVO: CONSTRUINDO O MERCOSUL DOS POVOS COM DEMOCRACIA E CIDADANIA, 2007, p. 15).

Os objetivos deste programa foram divididos em três eixos principais: 1) fortalecer a sociedade civil do Mercosul e gerar cidadania; 2) ampliar a 
democratização do Mercosul; 3) enfatizar os passos positivos do Mercosul. Portanto, através destes três eixos, o Estado mantem a posição central no processo de integração regional, mas visaria articular as posições entre os setores do poder executivo e parlamentar, com os movimentos sociais, nacionais e regionais, em prol de uma agenda positiva para a integração. Esta estratégia busca consolidar uma aliança entre os setores progressistas e os respectivos governos, na qual, se pretende fortalecer a política de democratizar o Mercosul, criando espaços para a sociedade civil e lideranças locais.

Na cidade de Córdoba, Argentina, em 2006 ocorreu o I Encontro por um Mercosul Produtivo e Social, no qual, as organizações sociais reuniram-se pela primeira vez nos marcos de um encontro presidencial e formularam as bases do programa. Através do apoio da Secretaria Geral da presidência da República do Brasil, durante a fase de preparação do evento, as organizações da sociedade tiveram acesso a informações de órgãos do governo federal que atuam no Mercosul, permitindo assim, uma dinâmica participativa, e de reflexão na cultura democrática e nos debates políticos (MERCOSUL SOCIAL E PARTICIPATIVO: CONSTRUINDO O MERCOSUL DOS POVOS COM DEMOCRACIA E CIDADANIA, 2007). Esse precedente também foi importante para que, em dezembro do mesmo ano, fosse convocada a I Cúpula Social do Mercosul, através do programa "Somos Mercosul", que demonstrou ter capacidade de construir ferramentas de participação social e um acompanhamento mais abrangente e democrático nos processos de integração desenvolvidos pelo Mercosul.

\section{CÚPULA SOCIAL DO MERCOSUL - CSM}

No intuito de suprir a necessidade de uma maior participação social nos mecanismos do Mercosul, foi criada a Cúpula Social do Mercosul em 2006. Interessante observar que a CSM foi vinculada à Cúpula de Chefes de Estado para que ambas cúpulas acontecessem paralelamente e estivessem diretamente 
sob a coordenação do Estado-membro em função da presidência pro-tempore que acontece rotativamente entre os países partes (MARTINS, et. al. 2011).

As Cúpulas Sociais tem se inspirado nas experiências de participação social que já foram desenvolvidas, como por exemplo, o Orçamento Participativo e o Fórum Social Mundial. Sendo assim, boa parte desse conhecimento esta focalizado na ideia comum de governabilidade social, que é o entendimento de que os movimentos sociais têm um papel presente na gestão, implementação e acompanhamento das políticas públicas.

Na primeira reunião da Cúpula, foi estabelecido em sua Declaração Final que os governos apoiassem e estimulassem a participação direta das organizações da sociedade civil em todos os subgrupos de trabalho e nas reuniões especializadas do Mercosul. Igualmente, para fortalecer a institucionalização e diálogo social dentro do Mercosul, foi incentivado a que os governos criassem mecanismos para incorporar tais organizações como observadoras nas reuniões do Grupo do Mercado Comum $(\mathrm{GMC})^{2}$ e do Conselho do Mercado Comum ${ }^{3}$ (MERCOSUL SOCIAL E PARTICIPATIVO: CONSTRUINDO O MERCOSUL DOS POVOS COM DEMOCRACIA E CIDADANIA, 2007, p. 16).

Atualmente, setores como a organização da agricultura familiar, cooperativas, mulheres, pequenos e médios empresários, entre outros, contribuem para a elaboração das Cúpulas Sociais que são realizadas para regular a agenda oficial do bloco e representam um avanço na construção da agenda social e na adoção de um método de decisões mais transparentes, participativas e legítimas.

De acordo com Martins et. al. (2011), essas Cúpulas têm se transformado em espaços supranacionais de discussões e propostas de políticas públicas, nas quais se consolida a participação ativa dos representantes dos movimentos sociais, dos governos e dos diferentes órgãos do Mercosul. Estas Cúpulas tratam

\footnotetext{
2 Órgão executivo cuja função é a de assistir o Conselho nas decisões de natureza executiva, adotando resoluções. Informações disponíveis em: 〈http://www.urutagua.uem.br//03almeida.htm〉 Acesso em 12 de maio de 2017.

3 Órgão supremo do processo de integração, composto pelos Ministros de Relações Exteriores e de Economia, adota decisões. Informações disponíveis em: 〈http://www.urutagua.uem.br//03almeida.htm〉 Acesso em 12 de maio 2017.
} 
temas regionais, valorizam a cidadania ativa e legitimadora do processo de integração, dão maior transparência ao processo decisório, e conferem maior influência da esfera pública regional na definição de estratégias que consolidam uma cultura democrática da integração.

Algumas políticas de integração são elaboradas através das atividades de discussão realizadas pelas Cúpulas Sociais do Mercosul, nas quais, os grupos da sociedade civil se organizam para dialogar com os governantes com o intuito de apresentar as reivindicações sociais que favoreçam a promoção de políticas públicas regionais. A ideia é demonstrar a importância que os movimentos sociais possuem no acompanhamento de políticas públicas, reafirmando assim, a democracia participativa e solidificando a democracia representativa.

A primeira Cúpula Social foi sob a presidência Pro tempore brasileira, e nessa oportunidade se reuniram mais de 500 representantes de organizações da sociedade civil dos países integrantes do Mercosul. No encontro foram apresentadas sugestões dos movimentos sociais para serem implantadas no Mercosul, que foram entregues em 2007 para os presidentes dos países membros e associados. Posteriormente, as Cúpulas foram realizadas em várias cidades da região, primeiramente em Córdoba e Brasília (2006), e nos anos seguintes, em Montevidéu (2007), em Tucumã e em Salvador (2008), em Assunção e em Montevidéu (2009), por fim, em Isla Del Cerrito e em Foz do Iguaçu (2010), entre outros (SGPR, s/d, s/p).

Interessante observar que nestas Cúpulas têm participado não somente as organizações sociais dos Estados Partes, como também os representantes de organizações de Estados Associados, como Chile, Bolívia, Equador e Peru; e os países da União de Nações Sul-Americanas (Unasul). Também têm participado as organizações regionais e sub-regionais, como a Aliança Social Continental, a Coordenadora de Centrais Sindicais do Cone Sul, a Confederação de Produtores da Agricultura Familiar do Mercosul e a Associação LatinoAmericana de Organizações de Promoção ao Desenvolvimento. Ainda, dentre os setores representados, é expressiva a participação de organizações ligadas à educação, cultura, cidadania, agricultura familiar e ao movimento sindical (MARTINS, et. al. 2011). 
Os resultados dos debates realizados nas Cúpulas Sociais são apresentados nas Cúpulas de Chefes de Estado, para apreciação pelos presidentes do bloco mercosulino, garantindo assim maior interação com os movimentos e organizações sociais da região. Nesse sentido, levando em consideração o trabalho das Cúpulas Sociais e todos esses critérios elencados, é fundamental considerar sua importância e influência nos processos de integração. Os temas que foram priorizados pela instância máxima decisória do Mercosul, são bem próximos aos aprovados nas declarações das Cúpulas Sociais, demonstrando o impacto das organizações que compõe o Mercosul Social e Participativo da agenda institucional do bloco (MESQUITA, 2012).

Tendo em vista os resultados das Cúpulas Sociais, em 2006 foi proposto um Plano Estratégico de Ação Social do Mercosul (PEAS), discutido pela primeira vez, e depois incorporado à agenda do bloco. Em decorrência disso, em 2008 foi encaminhada ao Grupo do Mercado Comum (GMC) uma proposta de diretrizes, contendo vários aspectos a serem considerados como eixos de trabalho, tais como a erradicação da fome, o combate à pobreza e às desigualdades sociais; o fortalecimento da ajuda humanitária, dos Direitos humanos, da participação social, da circulação de pessoas e da diversidade; fomento à saúde, educação e cultura; maior integração produtiva, fortalecimento da agricultura familiar, da economia solidária e das cooperativas (MERCOSUL SOCIAL E PARTICIPATIVO: CONSTRUINDO O MERCOSUL DOS POVOS COM DEMOCRACIA E CIDADANIA, 2007).

As Cúpulas Sociais são organizadas com o apoio dos Programas 'Somos Mercosul' e 'Mercosul Social e Participativo' (MERCOSUL SOCIAL E PARTICIPATIVO, 2012, p. 6). Estas Cúpulas podem agregar eventos paralelos, como ocorreu em 2012, com a realização do Seminário Internacional "Desafios da Construção da Democracia no Mercosul". O interesse do Seminário era o de compreender e dar visibilidade as especificidades da democracia na América do Sul, analisando os desafios da relação Estado-Sociedade no contexto dos governos democráticos, e o papel dos movimentos sociais. $O$ ponto mais debatido nesse Seminário foi a participação Social no Mercosul, evidenciando várias questões entre as quais se destacaram a resistência que essa participação sempre enfrentou na região; a dificuldade constante de diálogo 
entre Estado e sociedade civil; a diferenciação entre a democracia representativa e a democracia participativa; a necessidade de cooperação entre sociedade civil e Governo, e a necessidade de a sociedade civil ser vista como protagonista dos espaços de participação (IDDH, 2012, p. 26).

$O$ desafio consiste em afirmar que essas iniciativas se tornem efetivamente um espaço para negociação entre os atores sociais na elaboração de políticas públicas para o bloco, pois caso contrário, serão apenas mais fóruns para debates sem nenhum resultado efetivo, como é questionado por Pereira (2011), até que ponto os fóruns e mecanismos podem introduzir alguma democratização no Mercosul.

\section{INSTITUTO SOCIAL DO MERCOSUL - ISM}

Em 2007 criou-se o Instituto Social do Mercosul (ISM), localizado em Assunção, Paraguai. No mesmo ano também foi aprovada a Declaração de Princípios do Mercosul Social que propõe a construção de um espaço onde convirjam demandas de uma cidadania participativa, conscientes de direitos, deveres e obrigações. A criação do ISM foi estabelecida através da decisão do Conselho do Mercado Comum - CMC n 03/07, no âmbito da Reunião de Ministros e Autoridades do Mercosul (RMAM). O Instituto foi criado com o propósito de fortalecer o processo de integração mercosulino e promover 0 desenvolvimento humano integral entre os países membros.

Assim mesmo, o ISM é decorrente da necessidade de melhorar a elaboração e implementação de políticas e programas regionais. O Instituto fundamentou-se como instância técnica permanente de pesquisa na área das políticas sociais, objetivando padronizar a coleta de dados e a pesquisa social nos países integrantes do bloco. Dentre seus eixos de atuação estão a articulação de políticas sociais no Mercosul por meio da análise e da promoção de iniciativas nacionais a serem desenvolvidas em programas sociais em nível regional. Portanto, estas iniciativas tem como objetivo fundamental combater a pobreza e a exclusão social, dando prioridade aos setores mais vulneráveis das populações afim de suprir as necessidades da região. Também, as iniciativas 
contemplam, de conformidade com os Objetivos do Milênio, estabelecer um sistema de informação para conciliar indicadores de mensuração da pobreza, da desigualdade e das oportunidades de inclusão social, através de programas de capacitação e de assistência técnica e promover assim, a cooperação horizontal a partir de uma maior inserção e participação da sociedade civil (MERCOSUL SOCIAL E PARTICIPATIVO: CONSTRUINDO O MERCOSUL DOS POVOS COM DEMOCRACIA E CIDADANIA, 2007).

Por outro lado, o ISM possui um corpo técnico que trabalha no campo das políticas socais implementando estratégias para reforçar a dimensão social do bloco. Desde 2011, foi iniciado um novo ciclo de funcionamento do instituto com a incorporação de funcionários que constituem a equipe técnica sob a liderança de um diretor responsável. O instituto é dividido em quatro departamentos: Investigação e Gestão da Informação; Promoção e Intercambio de Políticas Sociais Regionais; Comunicação; e Administração e Finanças. Cada departamento do ISM está representado por um Estado Parte do Mercosul.

No primeiro boletim do ISM foram dadas as diretrizes para que o Instituto construísse uma ponte interinstitucional com as cúpulas sociais, fazendo com que fosse possível elevar os níveis de informação, articulação e conteúdo das políticas sociais entre os órgãos do Mercosul e a sociedade. No entanto, é necessário ressaltar as dificuldades que tal iniciativa apresenta. Conforme a Decisão do Conselho de Mercado Comum -CMC № 8/11 a divisão das contribuições dos Estados Parte foi distribuída de forma gradual e proporcional. Brasil assumiu a responsabilidade de colaborar com 39\%, Argentina com $24 \%$, Uruguai com $13 \%$ e Paraguai com $14 \%$. Entretanto, essa contribuição vinda dos Estados é custosa, o que pode ocasionar uma fragilidade no funcionamento do instituto, pois sem recursos, não existe a possibilidade de ser implementado um trabalho efetivo e materializar os objetivos e funções pelos quais o Instituto foi estabelecido.

Interessante observar que o Programa Mercosul Social e Participativo (PMSP), apresenta finalidades semelhantes àquelas desenvolvidas pelo ISM, 0 qual, tem se consolidado na região como um órgão técnico-político, assessorando os governos na construção de políticas sociais regionais. O ISM cada vez mais se fortalece e através de iniciativas e programas regionais de 
cunho social, vem inserindo estratégias que levam a uma maior participação social no desenvolvimento da integração mercosulina nos últimos anos.

\section{PROGRAMA MERCOSUL SOCIAL E PARTICIPATIVO - PMSP}

O Programa Mercosul Social e Participativo (PMSP) foi instituído pelo governo brasileiro e visa ampliar ainda mais as oportunidades de participação da sociedade civil no Bloco, sendo conformado por representante dos Ministérios e lideranças de organizações sociais (MERCOSUL SOCIAL E PARTICIPATIVO, 2008). O PMSP foi instituído visando ampliar as oportunidades de participação da sociedade civil em todos os países que conformam o Mercosul. No caso brasileiro, o Governo Federal, através do Decreto n 6.594 de 6 de outubro de 2008, estabeleceu as diretrizes de implementação do referido Programa no âmbito da Secretaria Geral da Presidência da República e do Ministério das Relações Exteriores. Já no primeiro artigo do Decreto, fica claro o propósito do Programa tendo como objetivo "[...] promover a interlocução entre o Governo Federal e as organizações da sociedade civil sobre políticas públicas para 0 Mercado Comum do Sul-Mercosul" (PRESIDÊNCIA DAREPÚBLICA, 2008, s/p)

O Decreto consolidou um conjunto de ações voltadas para a ampliação da participação popular na condução do Mercosul, e entre elas, o Conselho Brasileiro do Mercosul Social e Participativo que tem como finalidade a divulgação das iniciativas do governo relacionados com os programas da integração social do Mercosul. São alguns dos seus principais objetivos:

\footnotetext{
- Divulgar as políticas, as prioridades, as propostas em negociação e outras iniciativas do governo brasileiro relacionadas ao MERCOSUL.

- Fomentar discussões no campo político, social, cultural, econômico, financeiro e comercial que envolvam aspectos relacionados ao MERCOSUL.

- Encaminhar propostas e sugestões que lograrem consenso, no âmbito das discussões realizadas com as organizações da sociedade civil, ao Conselho do Mercado Comum e ao Grupo do Mercado Comum do MERCOSUL. (MARTINS, et. al. 2011, p. 153).
}

O funcionamento do Conselho vem possibilitando o compartilhamento das informações e o debate de alto nível a respeito de temas prioritários na agenda 
do Mercosul. A implantação do mesmo foi resultado do amadurecimento do bloco, através das experiências do Programa Somos Mercosul e das Cúpulas Sociais. Participam do Conselho, representantes de centrais sindicais, confederações da agricultura familiar, pastorais sociais, movimento negro, cooperativas, organizações de pequenos e médios, mulheres, juventude, meio ambiente, educação e cultura, entre outros. As reuniões do Conselho contam com a presença de autoridades do governo federal e técnicos das Reuniões Especializadas, Reuniões de Ministros, Comissões e Subgrupos de Trabalho do Mercosul, e ocorrem quatro vezes ao ano, sempre antecedendo as reuniões do Grupo do Mercado Comum - GMC (MARTINS, et. al.2011, p.151-152).

Igualmente, o Conselho contribuiu para a proposta de projeto do Fundo de Convergência Estrutural e Fortalecimento (Focem) em 2009. Da mesma forma o Conselho recomendou estabelecer o intercâmbio com o Instituto Social do Mercosul, e aprofundar as discussões sobre os acordos extra-regionais do Mercosul, com representantes do Ministério das Relações Exteriores. Por fim, o Conselho sugeriu que o bloco priorizasse temas relacionados à educação, micro, pequena e média empresa e migrações, sem detrimento de outros temas que venham a ser incorporados (MERCOSUL SOCIAL E PARTICIPATIVO: CONSTRUINDO O MERCOSUL DOS POVOS COM DEMOCRACIA E CIDADANIA, 2010).

Assim como o Conselho, o Programa Mercosul Social e Participativo, desde a sua criação, tem buscado promover um debate efetivo com as organizações da sociedade sobre políticas públicas de implementação e negociação no âmbito do bloco. Na reunião do Programa Mercosul Social e Participativo de 2012, foi empreendido um programa de ações executado pelo governo. O elemento de destaque desta reunião foi de que além dos representantes governamentais, participaram desse encontro diversas organizações da sociedade civil tais como: Associação Brasileira de Organizações Não Governamentais; Associação Latino Americana de Micro, Pequenas e Médias Empresas; Associação Brasileira de Gays, Lésbicas e Transgêneros; Campanha Nacional pelo Direito à Educação; Confederação das Mulheres do Brasil; Conectas/Comitê Brasileiro de Direitos Humanos e Política Externa; Conselho Nacional de Juventude; Coordenação Nacional de Entidades 
Negras; Espaço sem Fronteiras; Federação de Trabalhadores da Agricultura Familiar; Federação Democrática Internacional de Mulheres; Foro Consultivo Econômico e Social do Mercosul; Fórum Brasileiro de Economia Solidária; Instituto de Desenvolvimento da Cooperação e Relações Institucionais; Instituto de Desenvolvimento e de Direitos Humanos; Instituto de Estudos Socioeconômicos; Instituto Pólis; Programa Mercosul Social e Solidário; Rede Brasileira pela Integração dos Povos; e Serviço Pastoral do Migrante (SGPR, 2012).

Dessa forma, percebe-se que, contrário ao fundamento inicial do bloco de instituir apenas a integração econômica para a liberalização do comércio entre os países membros, verificasse uma abertura da agenda para 0 desenvolvimento da proteção dos direitos fundamentais da sociedade mercosulina significando o avanço da integração regional. $O$ bloco atua levando em conta as decisões dos cidadãos, que iniciam uma jornada de conscientização da importância dessa integração para melhorar as suas condições sociais e culturais, atuando com os Estados Membros para facilitar o acesso das demandas locais aos respectivos governos e, assim, acrescentar o Mercosul Social e Participativo como modelo de política pública a ser usada tanto no âmbito interno quanto regional (CABRAL, et. al. 2013).

\section{BALANÇO DAS EXPERIÊNCIAS SOCIAIS DO MERCOSUL}

O Mercosul tem pretendido fortalecer os canais de diálogo entre os diferentes setores sociais, favorecendo uma maior participação dos movimentos sociais na elaboração de políticas comuns aos países do bloco. Ao estabelecer novas agendas politicas e sociais, este bloco deixa de ser eminentemente comercial para pensar a política de integração regional de cunho social. Isto permite estabelecer novas agendas políticas entre os governos, possibilitando um diálogo mais amplo com os setores sociais.

Por isso, mecanismos como estes de participação cidadã no Mercosul, direcionam uma nova integração, não somente física e produtiva, mas também um novo processo que permita reduzir as assimetrias regionais através da 
integração cidadã e do incremento da participação social. Assim, conforme argumentam Lima e Coutinho sobre a experiência do Mercosul na primeira década do século XXI:

[...] os anos 2000 passam a se caracterizar por uma mudança de paradigmas do regionalismo aberto para a integração física e produtiva, e de um modelo do tipo rule-driven (dirigido por regras) para outro do tipo policy-driven (dirigido por políticas), no qual ideias de territorialidade, identidade e construção concreta de um espaço regional vêm à tona, inclusive com o retorno do Estado para o centro do palco, atuando como indutor - agora em maior parceria com a iniciativa privada - de um projeto de integração permanente [...] (LIMA, M.; COUTINHO, M. 2006, p. 14).

Esse policy-driving que vem sendo implementado ao interior do Mercosul tem favorecido a participação gradual e constante da sociedade civil nas decisões governamentais da integração, permitindo que alguns setores como redes de agricultura familiar, pastorais sociais, cooperativas diversas, pequenos e médios empresários, assumam um peso maior nas discussões sobre os destinos do Mercosul.

Nesse mesmo intuito, o bloco passa agora a ser pensado como uma rede dialógica de discurso entre os diferentes setores da sociedade civil e os governos. Por isso, conforme explicam Martins e Silva (2011), dentro do Mercosul se constitui uma nova esfera pública regional com ações positivas em áreas distintas, acompanhadas de resultados evidentes que beneficiam aos cidadãos mercosulinos. Os autores exemplificam o nível de aprofundamento de tal esfera, através de diversos casos de políticas comunitárias de integração regional para além da comercial:

O Acordo Multilateral da Seguridade Social dos Estados Partes permite, desde 2006, o acesso a direitos previdenciários no bloco; o atendimento médico em cidades de fronteira e a adoção de critérios comuns de saúde pública; a harmonização de currículos do ensino superior e das políticas públicas de educação; a promoção de ações conjuntas para o enfrentamento da violência contra a mulher; e a construção e negociação do Plano Estratégico de Ação Social configuram uma inédita base para o avanço da integração social. [...] Também se destaca a criação de mecanismos de financiamento e crédito para as atividades de interesse social, como o Fundo Mercosul de Garantias para as Micro, Pequenas e Médias Empresas e o Fundo de Agricultura Familiar do Mercosul. O objetivo é priorizar as principais 
fontes de geração de empregos e garantir a segurança alimentar regional (MARTINS e SILVA, 2011, s/p).

Por outro lado, no relacionado com o aprofundamento da democracia na região através do processo de integração, é importante estabelecer que para lograr tal fim, se torna necessário garantir os direitos civis, políticos e sociais dos cidadãos. Assim, a dimensão social da integração mercosulina se configura como um espaço inclusivo ao fortalecer os direitos dos cidadãos e, por conseguinte, fomentar a permanência e continuidade democrática no bloco.

Por sua vez, em 2012, o Brasil assumiu a presidência Pro-Tempore do Mercosul, fato que significou ao país o ápice de um processo de reflexão e diálogo social sobre a integração regional e a participação social no Bloco. O governo brasileiro tem contribuído de forma positiva em relação aos programas sociais, através de uma agenda ampliada com a adoção de políticas inclusivas e de acesso geral a bens públicos básicos como saúde, educação, habitação, entre outros.

Na XIX Cúpula, realizada em Brasilia em 2012 foi aprovado o "Plano de Ação 2013-2014" do "Fórum Consultivo de Município, Estados Federados, Províncias e Departamentos do Mercosul' (SECRETARIA EXECUTIVA DE MERCOCIDADES 2012-2013; SECRETARIA TECNICA PERMANENTE DE MERCOCIDADES (2013), p. 22). Nessa oportunidade foram realizadas oficinas temáticas, cada uma discutindo assuntos previamente selecionados pela sociedade civil, e foi concluída a Declaração de Brasilia. Ao final foram produzidas um total de vinte propostas, nas quais podem ser destacadas:

[..] a harmonização das legislações migratórias, o livre trânsito dos produtos e serviços da economia social, solidária e popular, o ensino de disciplinas como Culturas Latino-Americanas e Direitos Humanos e das línguas portuguesa e espanhola, leis que democratizem a comunicação e políticas que expandam o acesso a internet, além da ampliação do escopo dos fundos de financiamento do Mercosul para abarcar projetos sociais (CÚPULA SOCIAL DO MERCOSUL, 2012, $\mathrm{s} / \mathrm{p})$.

Em dezembro 17 de 2014, o Brasil assumiu novamente a presidência Pro Tempore do Mercosul, com efeito a partir de 2015. A presidenta Dilma Rousseff ressaltou, em seu discurso, a necessidade de aperfeiçoar os mecanismos 
sociais do Mercosul, como também a renovação do FOCEM voltado para diminuição das assimetrias entre os países do bloco. Com relação ao aspecto social, foi de destaque pela presidenta, o fato de que os mecanismos e modelos de desenvolvimento para inclusão social, adotado no Mercosul, tenham contribuído com a diminuição dos efeitos colaterais da crise econômica mundial que se arrasta desde 2008 (PORTAL BRASIL, 2014).

É importante salientar que na medida em que projeto do Mercosul Social se constitui como um espaço de abertura da burocracia institucional do processo de integração do Mercosul às necessidades da sociedade civil, tal espaço ainda é considerado muito delimitado para a participação da população. Existem momentos previamente definidos em que a cidadania organizada é convidada a assistir e se envolver nos encontros e reuniões institucionais. Dessa forma, por vezes a iniciativa pertence a organismos dos Estados Partes, e eles são os que definem quem vai participar nos temas que serão debatidos (PEREIRA, 2011).

Nesse aspecto, podem ser levantadas algumas falhas na elaboração dessa política participativa, pois, delimitam o espaço participativo do bloco somente a momentos bem definidos e específicos, restringindo a possibilidade de desenvolvimento de uma cidadania supranacional. Assim, o Mercosul Social e Participativo passa a ser visto como uma iniciativa com participação restrita, percebido mais como um fórum de debates.

Alemany e Leandro (2006) argumentam que existe uma série de debilidades que fragilizam a participação social no Mercosul. Tais debilidades estão focalizadas na representação exercida pelos membros, no funcionamento do regulamento interno dos programas sociais da integração, na articulação dos grupos sociais que participam dos encontros, e na incidência que os grupos têm para implementar e supervisionar as políticas acordadas para os níveis regionais e locais. Dessa forma, para que seja construído um bloco de integração social fortalecido, deverá ser feito um esforço para democratizar a informação e redesenhar a participação cidadã.

É notório que essas políticas sociais ainda são consideradas insuficientes, pois se desenvolvem lentamente e não contam plenamente com espaços institucionais adequados. Entretanto, isso não significa que não houve nenhuma mudança, pois cada vez mais é explícita a transição de um Mercosul, 
inicialmente comercial, para um bloco mais social e participativo. Anteriormente, o processo de integração mercosulina era unicamente pensado para resolver os problemas econômicos e industriais, atualmente conta como uma instituição regional voltada para participação efetiva de parcelas da sociedade civil.

Essas iniciativas que foram apresentadas ainda são recentes para conseguirmos avaliar os efeitos que poderão provocar rumo à consolidação da integração social do Mercosul. No entanto, as políticas de harmonização social, apesar de só conquistar notoriedade nos últimos anos, refletem uma crescente conscientização, "tanto da parte dos governos, quanto da parte das sociedades, de que o Mercosul já não prescinde da integração social e da participação da sociedade civil para continuar avançando" (MARTINS, et. al. 2011, p. 160). Assim, é fundamental a ampliação do Mercosul Social e Participativo, para que seja construída efetivamente uma democracia regional, refletindo positivamente no processo integracionista e correspondendo aos anseios da sociedade civil.

\section{CONSIDERAÇÕES FINAIS}

O presente trabalho objetivou estudar a dimensão social do processo integracionista do Mercosul. $\mathrm{Na}$ análise feita, constatou-se que existe a necessidade de que em tal processo sejam contemplados os demais níveis da sociedade além do comercial. Para tal objetivo, foram criadas diversas iniciativas dentro do Mercosul com o intuito de captar o interesse da sociedade civil dos Estados-membros, para facilitar o envolvimento da participação social. No decorrer do artigo, foram explanadas diversas iniciativas que o bloco vem promovendo e reafirmando a importância dessas ações para a consolidação democrática intra-bloco, levando em conta a participação da sociedade civil no processo mercosulino.

Esse novo padrão de políticas geradas dentro do Mercosul demonstram a importância que as demandas sociais adquiriram nos últimos anos. Mesmo que o processo de integração do Cone Sul tenha sido criado, inicialmente, com fins comerciais e tenha sido pensando como solução para os problemas econômicos, 
atualmente, o processo oferece novas funções, nas quais, a participação efetiva da sociedade civil organizada permite com que os cidadãos se aparelhem em redes de incidência pública regional. Nesse sentido, a integração regional passa a envolver, discutir e implementar temas distintos daqueles propostos inicialmente, e assim se vislumbra a possibilidade gradual de que o Mercosul contemple o potencial da sociedade civil no fortalecimento e amadurecimento da democracia regional.

Observou-se que, nos últimos anos, o envolvimento de atores sociais nesse processo de integração sul-americano cresceu de maneira relevante. No Mercosul encontramos canais de participação para a atuação, como os programas Mercosul Social e Participativo, que consiste num processo de fortalecimento cidadão através da representação das demandas sociais. Esses fatores tem resultado positivo na integração regional, pois proporcionam espaços para discussão e consolidação de soluções a problemas comunitários. Assim, a democracia se constitui como um pilar importante e a participação social se torna imprescindível no aprofundamento do processo da integração regional.

O surgimento das iniciativas 'Somos Mercosul', das Cúpulas Sociais, do Instituto Social do Mercosul, e do Programa Mercosul Social e Participativo, representa passos importantes para a efetivação das políticas sociais do bloco. Essas conquistas tornaram-se possíveis através das mudanças políticas, econômicas e sociais decorrentes da inserção das questões sociais nos interesses comunitários da integração regional. As experiências derivadas desses programas devem ter continuidade para complementar a transição do Mercosul Social no aprofundamento da integração regional.

Importante destacar que Mercosul pode ser cada vez mais democrático na medida em que os processos integracionistas sejam entendidos como projetos de coesão econômico social, capazes de diminuir as disparidades regionais e sociais dentro do bloco de conformidade com interesses dos cidadãos. Dessa maneira, a integração deve avançar de modo que influencie o cotidiano das populações envolvidas, criando condições para a mobilização delas em prol do interesse da sociedade civil.

Igualmente, a integração deve promover a participação dos atores sociais e gerar equidade dentro dos países do Mercosul, aumentando a participação 
popular e visando garantir a representação dos interesses de forma igualitária. As Cúpulas Sociais, por exemplo, tem o objetivo de incorporar os setores que queiram contribuir com a integração.

No entanto, deve-se reconhecer que as ações que estão sendo realizadas se desenvolvem lentamente e muitas vezes elas não contam com os ambientes de interação pertinentes para serem aprimoradas. Porém, apesar desses empecilhos, podemos observar que houveram avanços através da ampliação da esfera pública regional em muitas áreas do bloco, como a social, a educação e a saúde, revelando que o Mercosul reverteu a lógica unicamente comercial da sua primeira fase (MARTINS, et. al. 2011).

Em meio às observações apresentadas, é possível concluir que o bloco precisa enfrentar desafios como a ampliação da participação social, pois a interação e presença da sociedade, em relação ao esperado, ainda é limitada. Entretanto, o Mercosul está avançando em relação aos demais blocos de integração sul-americanos no quesito de participação civil. O processo mercosulino conta com espaços que promovem um maior diálogo com os movimentos sociais que, através das diferentes organizações comunitárias, fortalecem os princípios democráticos na tomada de decisões políticas de alcance regional.

A consolidação do Mercosul Social depende da articulação das organizações sociais, como também a decisão política de abrir cada vez mais o caminho para a participação social. Por todo o exposto, confirma-se que o Mercosul Social e Participativo promove uma efetiva inserção da sociedade na integração, instituindo-se como um espaço para manifestação de propostas a serem apresentadas na busca de soluções aos problemas enfrentados pelo conjunto das comunidades locais e regionais.

\section{REFERÊNCIAS}

ALEMANY, Cecilia; LEANDRO, Beatriz. Análisis y Propuestas para La Participación Ciudadana en el MERCOSUR. Montevideu: Friedrich Ebert Stiftung Fesur, 2006.

CABRAL, Cristiane; ANDRADE, Mayra; JUNIOR, Bruno. A Integração que deu Certo: O Mercosul Social e a Efetivação dos Direitos Fundamentais. Revista FSA. Faculdade 
Santo Agostinho. Teresina, Vol. 10, No. 4, Art. 7, Out./Dez. 2013. Disponível em: <http://www4.fsanet.com.br/revista/index.php/fsa/article/view/202/126> Acessado em: 12 de maio de 2017.

CONSELHO DO MERCADO COMUM -CMC. Decisão no 03/07. Instituto Social do Mercosul. 2007. Disponível em: <http://www.sice.oas.org/trade/mrcsrs/decisions/dec0307p.pdf> Acessado em 12 de agosto de 2017.

. Decisão no 8/11. Contribuições para o Orçamento do Instituto Social do Mercosul. 2011. Disponível em: <http://dai-mre.serpro.gov.br/atosinternacionais/multilaterais/decisao-cmc-no-8-11-contribuicoes-para-o-orcamento-doinstituto-social-do-mercosul/> Acessado em 16 de setembro de 2017.

CÚPULA SOCIAL DO MERCOSUL 2012. Declaração de Brasília. 2012. Disponível em: <http://socialmercosul.org/declaracao-de-brasilia> Acessado em 02 de outubro de 2017.

20 Propostas para a Democracia Sul Americana. 2014. Disponível em: <http://socialmercosul.org/20-propostas-para-a-democracia-sul-americana/> Acessado em 16 de outubro de 2017.

DRAIBE, Sônia. América na encruzilhada: Estaria emergindo um novo Estado desenvolvimentista de Bem Estar? Observações sobre a proteção social e a integração regional. Caderno de Pesquisa No. 78. Núcleo de Estudos de Políticas Públicas-NEPP. Campinas: Editora Unicamp. 2006. Disponível em: $<$ http://www.nepp.unicamp.br/images/pdfs/caderno78.pdf> Acessado em 04 de outubro de 2017.

FREITAS, Valter. A Circulação do Trabalho no Mercosul e na União Europeia. Santa Cruz do Sul: EDUNISC, 2009.

INSTITUTO DE DESENVOLVIMENTO E DIREITOS HUMANOS - IDDH. Relatório Direitos Humanos e Participação Social no Mercosul 2012- Documento Paralelo Relato das Reuniões. $2012 . \quad$ Disponível em: <http://www.iddh.org.br/v2//upload/282e25a4dac24e36cf84ac2f3be819b9.pdf> Acessado em 02 de outubro de 2017.

LIMA, Maria; COUTINHO, Marcelo. (2006). Integração Moderna. Análise de Conjuntura OPSA, Observatório Político Sul-Americano. Instituto Universitário de Pesquisas do Rio de Janeiro IUPERJ/UCAM. No. 1; Janeiro de 2006. Disponível em: <http://www.plataformademocratica.org/Publicacoes/22207.pdf> Acessado em 13 de maio de 2017.

MARTINS, José; SILVA, Carolina. Políticas Sociais e Participação Social: A constituição de uma esfera pública regional no Mercosul. Boletim de Economia e Política Internacional. IPEA. $\quad$ n. 05, 2011. Disponível em: <http://www.ipea.gov.br/desafios/index.php?option=com_content\&view=article\&id=261 2:catid=28\&ltemid=23> Acessado em 30 de outubro de 2017.

MARTINS, José; ALBUQUERQUE, Carolina; GOMENSORO, Federico. MERCOSUL Social e Participativo: a ampliação da esfera pública regional. In: CAETANO, Gerardo (org.). Mercosur 20 años. Montevideu: CEFIR. 2011.

MERCOSUL SOCIAL E PARTICIPATIVO. Presidência Pro Tempore Brasil. 2008. Disponível em: <http://secretariageral.gov.br/.arquivos/mercosulsocialeparticipativo> Acessado em 10 de setembro de 2017.

MERCOSUl SOCIAL E PARTICIPATIVO: Construindo o Mercosul dos Povos com Democracia e Cidadania. Brasília: lbraes. 2007. Disponível em: 
$<$ http://www.spm.gov.br/assuntos/acoes-internacionais/Articulacao/articulacaointernacional/mercosul/livro-mercosul-social-participativo.pdf> Acessado em 10 de setembro de 2017.

.Brasília: lbraes, 2010. Disponível em: <http://ismercosur.org/wpcontent/uploads/downloads/2012/09/Mercosul_Social-e-Participativo-2010.pdf> Acessado em 10 de setembro de 2017.

MERCOSUL; REUNIÃO DE MINISTROS E DIRETORES DE DESENVOLVIMENTO SOCIAL (RMADS); INSTITUTO SOCIAL DO MERCOSUL. A Dimensão Social do Mercosul: Marco Conceitual. Assunção: Produção Editoral Tekoha, 2012.

MESQUITA, Lucas. Para além do Estado: A Agência no Mercosul Social e Participativo. Conjuntura Internacional, vol. 10, n. 1, p. $40-50,1^{\circ}$ sem. de 2013. Disponível em: <http://periodicos.pucminas.br/index.php/conjuntura/article/viewFile/5260/5224> Acessado em 20 de outubro de 2017.

PEREIRA, Fabrício. Democratização Supranacional? O caso do Mercosul. Revista Orbis Latina, vol 1.2011 .20 Disponível em: <http://issuu.com/gilsonoliveira/docs/orbis_latina> Acessado em 20 de outubro de 2017. PORTAL BRASIL. Dilma assume presidência do Mercosul. Governo. 2014. Informação disponível em: <http://www.brasil.gov.br/governo/2014/12/dilma-assume-presidenciado-mercosul> Acessado em 16 de outubro de 2017.

PRESIDENCIA DA REPÚBLICA - Casa Civil, Subchefia para Assuntos Jurídicos. Decreto 6.594 de 6 de Outubro de 2008. Institui o Programa Mercosul Social e Participativo. Disponível em: <http://www.planalto.gov.br/ccivil_03/_Ato20072010/2008/Decreto/D6594.htm > Acessado em 12 de maio de 2017.

RANZAN, Eduardo. O Mercosul no século XXI: Combatendo assimetrias e ampliando o diálogo. Monografia para curso de Relações Internacionais da Faculdade de Ciências Econômicas da UFRGS, Porto Alegre, 2011. Disponível em: <http://www.lume.ufrgs.br/bitstream/handle/10183/40272/000826880.pdf?sequence $=1$ > Acessado em: 04 de setembro de 2017

SECRETARIA EXECUTIVA DE MERCOCIDADES 2012-2013; SECRETARIA TECNICA PERMANENTE DE MERCOCIDADES. Informe da Secretaria Executiva e Secretaria Técnica Permanente de MERCOCIDADES Período 2012-2013. Quilmes e Montevidéu: Multiformas SRL 2013. Disponível em: <http://portal.mercociudades.net/sites/portal.mercociudades.net/files/archivos/documen tos/Publicaciones/InformeAnualPort_2012_2013.pdf> Acessado em 12 de maio de 2017.

SECRETARIA GERAL DA PRESIDÊNCIA DA REPÚBLICA - SGPR. Cúpula Social do Mercosul. s/d.

em: <http://www.secretariageral.gov.br/atuacao/internacional/mercosul-social-eparticipativo/textofinal> Acessado em 12 de maio de 2017.

Programa Mercosul Social e Participativo define ações para Presidência Pro Tempore Brasileira do Bloco. 2012.2 Disponível em: <http://www.secretariageral.gov.br/noticias/2012/03/13-03-2012-programa-mercosulsocial-e-participativo-define-acoes-para-presidencia-pro-tempore-brasileira-do-bloco> Acessado em 02 de outubro de 2017.

STUART, Ana. Regionalismo e democracia: uma construção possível. Tese do Centro Brasileiro de Relações Internacionais CEBRI, s/d. Disponível em: <http://www.plataformademocratica.org/Publicacoes/7060_Cached.pdf> Acessado em 10 de setembro de 2017. 
TRATADO DE ASSUNÇÃO. 1991. Disponível em: <http://www.tprmercosur.org/pt/docum/Tratado_de_Assuncao_pt.pdf> Acessado em 02 de setembro de 2017.

VÁZQUEZ, Mariana. Los escenarios de participación social en el Mercosur. In: $1^{\circ}$. CONGRESO LATINOAMERICANO DE CIENCIAS SOCIALES - 50 AÑOS DE FLACSO, Quito: $\quad$ FLACSO, 2007. Disponível em: <http://www.flacsoandes.edu.ec/sites/default/files/agora/files/1215191993.los_escenari os_de_participacion_por_mariana_vazquez_3.pdf> Acessado em 20 de agosto de 2017.

Recebido em 06 de setembro de 2017. Aprovado em 09 de dezembro de 2017. 